\title{
Origen y desarrollo de la actividad filmotecaria en España. Implementación y singularidad del mapa filmotecario español ante el nuevo contexto digital (1954-2012)
}

\author{
Pablo García CASAdo \\ Junta de Andalucía \\ pablo.garcia@juntadeandalucia.es \\ Jordi Alberich PASCUAL \\ Universidad de Granada \\ jalberich@ugr.es
}

\begin{abstract}
Resumen:
El presente artículo realiza el estudio genealógico del actual mapa filmotecario español, en el que cohabitan quince filmotecas autonómicas, además de tres locales y una estatal. Exploramos los inicios en España de la preservación del patrimonio fílmico en los años 20, y cómo ese deseo se abre paso con suma dificultad. Tras el paréntesis forzoso de la Guerra Civil (1936-1939), atendemos a su revitalización hasta culminar en la creación de la primera Filmoteca Nacional (1954). Finalmente, abordamos el proceso de expansión territorial de la actividad filmotecaria que se abre con la Constitución Española de 1978.
\end{abstract}

Palabras clave: Filmotecas; Filmotecas autonómicas; Historia; Orígenes; España.

Origin and development of film archive activity in Spain. Implementation and uniqueness of Spanish film archive map on the new digital environment (1954-2012).

\begin{abstract}
:
This article makes the genealogical study of the current Spanish film archive map, which is inhabited by fifteen regional film archives, plus three local and one state. We explored the beginnings of film preservation in the 20s in Spain, and how that desire breaks through with difficulty. After the interruption forced by the Civil War, we attend to its revitalization, culminating in the creation of the first National Film Archive (1954). Finally, we address the process of territorial expansion of film archive activity that opens with the Spanish Constitution of 1978.
\end{abstract}

Key Words: Film Archives; Regional Film Archives, Origin; History; Spain.

Referencia normalizada:

García Casado, P. y Alberich Pascual, J. (2014): Origen y desarrollo de la actividad filmotecaria en España. Implementación y singularidad del mapa filmotecario español ante el nuevo contexto digital (1954-2012). Historia y Comunicación Social. Vol. 19. Núm. Especial Enero. Págs. 279-289. 
Sumario: 1. Introducción. 2. Objetivos y metodología. 3. Genealogía de la actividad filmotecaria española. 4. Desarrollo y singularidad del mapa filmotecario español: las filmotecas autonómicas. 5. Conclusiones. 6. Referencias bibliográficas. 7. Notas.

\section{Introducción}

Desde que los hermanos Lumière proyectaron en 1895 las primeras imágenes en movimiento surgió la pregunta de qué hacer con todos esos rollos de material fílmico que el invento tendía a acumular. Piezas pesadas, costosas, cuyo valor económico mantenía un rendimiento decreciente; una vez que la proyección se mostraba en las ferias del entorno el público dejaba de interesarse por ellas a la espera de otra novedosa. Las empresas y las personas que se manejaban en ese nuevo mundo del cinematógrafo no eran conscientes del enorme valor que la conservación de esos materiales tendría para el futuro, y se estima habitualmente que más del $80 \%$ de la producción fílmica de los primeros veinte años de vida del cinematógrafo acabaron destruidos (Borde, 1991: 13).

Aunque la destrucción fílmica tiene originalmente una explicación económica (Seguin, 2002), hay que buscar también razones intrínsecas al propio hecho cinematográfico, al propio estatuto jurídico del bien fílmico, pues de acuerdo con "el poder del derechohabiente" (Borde, 1991: 33), el productor o la entidad o persona a quien se haya transferido la propiedad del film, tiene un poder absoluto sobre los negativos y las copias derivadas de ese derecho. Puede entregarlo a un archivo cinematográfico para evitar su deterioro y promover que sea también testigo de un tiempo; puede revenderlo a los coleccionistas privados, en un mercado cada vez más en auge; o puede destruir y hacer que se destruyan las copias, y nadie puede impedírselo, ni siquiera el Estado (1).

Junto a ambos argumentos previos (económico y jurídico), cabe considerar también la difícil adecuación del material fílmico -como soporte de producción en serie- a los esquemas clásicos de la obra de arte. De alguna manera, el cine como manifestación artística, desdice el cliché de la originalidad y de la irrepetibilidad. Además, su relativa juventud, de poco más de una centuria, la hace ser menos permeable a la vocación conservadora que recae sobre otras piezas denominadas de interés cultural. De acuerdo con Alfonso del Amo, "La conservación de la cinematografía, entendida como Preservación del Patrimonio Cultural, no está entre los objetivos de la industria. (...) La industria no puede permitirse actividades conservacionistas que, al comprometer la inmediata obtención de beneficio, condicionan su desarrollo económico" (Del Amo, 1991: 14).

Podemos establecer por tanto que la destrucción es un hecho intrínseco al fenómeno fílmico, un vector que ha tenido su respuesta en el movimiento filmotecario mundial. Un movimiento que nace en la década de los la década de los 20 y principios de los 30 del siglo pasado, en el que coinciden en el tiempo iniciativas de entidades privadas y de gobiernos europeos para reunir los archivos fílmicos bajo un mismo 
organismo. Sin embargo, no es hasta 1933 cuando se crea la primera Filmoteca, la Swenska Filmsamfundet sita en Estocolmo (Sundholm, 2006: 18). A ella la siguieron la de Berlín, Milán, Nueva York, París y Londres (Low, 1997: 4).

Tiene además este movimiento filmotecario una vocación universalista; al poco de la fundación de esas primeras filmotecas, se constituye en 1938 la Federación Internacional de Archivos Fílmicos. Y nada más concluir la Segunda Guerra Mundial, se plantea una reunión anual de la FIAF en Praga (1945), en Ámsterdam (1946) Varsovia (1946), reuniendo a países de un lado y otro del Telón de Acero (Surowec, 2002). El éxito del movimiento filmotecario internacional es indudable. Cuando fue fundada en 1938, la FIAF contaba con cuatro miembros. Hoy día agrupa a más de 150 instituciones pertenecientes a más de 77 países, aspecto éste que nos da la medida de que se trata de un movimiento transfronterizo que revela un interés por la preservación del patrimonio de las imágenes en movimiento a nivel mundial.

\section{Objetivos y metodología}

La planteamiento discursivo de este trabajo se fundamenta en que la emergencia histórica de las filmotecas dió respuesta a la barbarie destruccionista de las tres primeras décadas del siglo XX para con el patrimonio fílmico. Esa función, definida y concretada hasta los años 90 del siglo pasado, necesita ser revisada y actualizada ante el nuevo reto digital, que no supone un cambio tecnológico más, sino una auténtica transformación de paradigma cultural.

En este trabajo revisamos hasta qué punto las bases que fundaron el movimiento filmotecario español a mediados del siglo pasado siguen vigentes en plena era digital, con la existencia de un inmenso aluvión de imágenes en movimiento que se generan a cada segundo en el mundo. La respuesta, como es lógico, debe abordarse desde distintos puntos de vista, por cuanto la dimensión de esta institución y su relación con la realidad contemporánea es también plural. Para ello, exploraremos los primeros indicios de una voluntad conservadora del patrimonio en nuestro país, y cómo ese deseo se abre paso frente a las poderosas fuerzas de la propiedad industrial e intelectual y las fronteras que han existido a la posibilidad de unos circuitos normalizados de intercambio de películas entre diversos territorios.

Nuestra aproximación metodológica está determinada por la escasez de material bibliográfico y de literatura científica de impacto sobre el tema. Las referencias en bases de datos sobre archivos fílmicos tienden sobre todo a la especialización, a casos muy concretos de restauraciones y de análisis retrospectivos de cinematografías, pero son pocas las muestras de una bibliografía adecuada sobre el papel que han jugado o que deben jugar las filmotecas españolas (o internacionales) en la sociedad contemporánea.

El presente estudio ha conjugado investigación básica y aplicada, descriptiva y de campo. El proyecto se ha desarrollado mediante la recolección de datos sobre 
las actividades de las filmotecas españolas, e igualmente hemos interactuado con las filmotecas seleccionadas a nivel general e individual, además de realizar visitas puntuales a dichas filmotecas. Así, se han estudiado los aspectos particulares de cada filmoteca y se ha establecido una propuesta clasificatoria de las mismas. En este sentido la observación y uso de las fuentes legislativas ha resultado de fundamental importancia, permitiendo recabar adecuadamente la información acerca de la implementación y singularidad del mapa filmotecario español.

\section{Genealogía de la actividad filmotecaria española}

El movimiento filmotecario español no se inicia oficialmente hasta la constitución en 1954 de la Filmoteca española. ¿Es que en nuestro país no existía interés por la defensa de la cultura cinematográfica? Sí que existía, lo que ocurre es que, como diría el pintor Juan Cuenca, "en los años 50 había que inventarlo todo de nuevo"(2). Y esto implicaría no sólo la reinvención de un país en ruinas, sino el establecimiento de una primigenia política cultural.

Durante el reinado de Alfonso XIII, especialmente durante el Primer Congreso Español de Cinematografía celebrado en Madrid en 1928, se evidencian los primeros precedentes de intentos personales y colectivos que demandan un cierto grado de protección del patrimonio cinematográfico español, en el que se resuelve, en sus conclusiones, la necesidad de lanzar desde el ministerio de Trabajo un Cinemateca Nacional. Esta demanda desembocó en una Real Orden del Ministerio en el que se crea el Comité Español de Cinema Educativo; y en otra más concreta, ya en tiempos de la II República, en la Orden de 30 de Junio de 1933 por la que se crea un servicio dependiente del Ministerio de Agricultura para el depósito de películas especializadas en esta materia. Por tanto, más que la vocación de conservación del patrimonio, lo que latía era una necesidad de preservar esas películas a la luz de esa segunda ola de destrucción que amenazaba la labor educativa y formadora que el cine había supuesto para este ministerio.

Tras el dramático y doloroso paréntesis que supuso la Guerra Civil a todo albor de construcción de una actividad filmotecaria, no será ya hasta los años 50, exactamente hasta el año 1953, cuando gracias al tesón de Carlos Fernández Cuenca se retomará la idea. Y así, por decreto de 13 de febrero de ese mismo año, se crea la Filmoteca Nacional, cuya misión es crear un archivo de películas y de documentación cinematográfica, procurando su mejor conservación y haciendo posible que el material archivado se utilice sólo con fines culturales. Pero, como tantas veces en España, el asunto de la Filmoteca quedó en papel mojado, sin dotación, sin edificio: una entelequia administrativa que vio pasar por delante, sin poder participar plenamente, las reuniones de las Conversaciones de Salamanca de 1955 o, más concretamente, los congresos de la FIAF de Estocolmo de 1958 -donde España se jugaba su admisión- y de Budapest, al año siguiente (García Mangas, 1995: 84). El aislamiento internacio- 
nal aún era una constante que no se superaría de manera efectiva hasta bien entrada la década de los 60 .

Esa etapa incipiente de la Filmoteca Española tiene su personificación en Florentino Soria, institución a la que éste llega de la mano del entonces Director General de Cine, García Escudero. En su etapa se inician los ciclos de Griffith, Eisenstein, Stroheim o Antonioni, y se establece la obligatoriedad de depósito de todas aquellas películas que hubieran obtenido alguna ayuda estatal. De acuerdo con su propio relato, "La conservación es lo esencial. No hay otra filosofía para una filmoteca. ¿Y qué es lo que hay que conservar? Todo el cine nacional que se pueda recuperar. Porque si cada país se preocupa de conservar su cine, quedará salvaguardado el patrimonio del cine universal" (Soria, 1987: 4).

A Florentino Soria le sucedería, con el primer gobierno del PSOE en España, Juan Antonio Pérez Millán, que, aunque su mandato fue relativamente breve, hizo posible la actualización de un nuevo concepto de filmoteca, más cercano y homologable a las filmotecas europeas, desde una reflexión sobre qué debe y qué no debe ser una filmoteca, en función de cuatro ejes: fondos fílmicos, documentación, difusión y cooperación, que constituyen los cuatro ejes sobre los que se asientan algunas de las filmotecas autonómicas, como la de Andalucía, que aparecerían dos años después. A Pérez Millán le sucedería en 1986 Miguel Marías; y por último, sería nombrado en 1989 José María Prado, quien se mantiene como director hasta nuestros días (3).

En su inauguración, allá por 1954 no estaban previstas las sesiones de proyección pública. Todo lo más estaban previstas a al apoyo a los incipientes cine-clubs, pero hubo que esperar hasta 1963 para encontrar un primer programa de proyecciones, que se desarrollaron en el Instituto Nacional de Previsión. No obstante, a pesar del trabajo realizado, la filmoteca constituía un lugar casi residual, e incluso durante 5 años, de 1967 a 1972, se detiene la programación, volviendo nuevamente al sistema de préstamo a Cine-Clubs. Como contraste, la Filmoteca Española ofreció unos ciclos temáticos en Barcelona y ya en los años 70, en Valencia.

"El año 75 es clave en el tema de la descentralización; se pide colaboración desde otras capitales de provincia que desean tener este servicio cultural" (García Mangas, 1995:109). No obstante, a pesar de los esfuerzos por satisfacer itinerancias, la Filmoteca carecía de los medios para llevar cine a las 52 provincias españolas. La falta de recursos y de copias propias, con lo que suponía de dependencia exterior, convertía esta proyección exterior en una suma de frustraciones. De hecho, esa tensión con la periferia, por satisfacer los deseos de otros territorios, llevó precisamente a que la sede de las proyecciones de la Filmoteca Española tuviese un azaroso recorrido hasta recalar en el Cine Doré desde 1989 y hasta la actualidad. 


\section{Desarrollo y singularidad del mapa filmotecario español: las filmotecas auto- nómicas}

La Constitución Española de 1978 abre un nuevo marco territorial donde las competencias sobre la acción cultural quedan progresivamente descentralizadas y abiertas a que las Comunidades Autónomas puedan desarrollar la labor de protección del patrimonio fílmico dentro de sus territorios. El sistema competencial de su artículo 149 fijan dos niveles de concreción para este fin. Por un lado, el Estado mantiene competencia exclusiva sobre archivos y museos que sean de titularidad estatal, pero posibilita la cogestión de estos espacios por las Comunidades Autónomas. Esto, leído desde la perspectiva de la acción cultural, deja un amplio campo de acción a las Comunidades para que desarrollen políticas culturales autónomas, máxime cuando existe una tremenda generosidad en las transferencias competenciales en materia cultural, lo que desemboca en una proliferación de filmotecas autonómicas.

El origen de esta pluralidad se explicaría en la insistencia de construir una identidad regional o nacional diferenciada, cristalizada con la formulación de una institución propia. Cada una de ellas, en sus estatutos y normas de constitución, expresa el deseo de reunir, conservar y defender el patrimonio fílmico de la comunidad en cuestión, expresión que puede resultar, cuando menos, discutible. Al fin y al cabo, la regionalidad de un film siempre es discutible. ¿Es estrictamente riojana la Calle Mayor, de Bardem? ¿Es exclusivamente catalana la Plaça del Diamant, de Betriu? ¿Es andaluz todo el costumbrismo de los años 50? ¿Habría que constituir una filmoteca autonómica en Madrid para conservar las copias de la comedia madrileña de los 80 ?.

Pese a esta aparente diáspora, de factores centrífugos semejantes a los de otros aspectos de la vida social española, hay otros factores centrípetos, que de alguna manera concretan la colaboración entre distintas instituciones que la Constitución Española eleva como propio, y que se articula en dos factores. El primero tiene que ver con la existencia de una institución superior homologadora como es la FIAF que aúna modos y actividades de colaboración entre filmotecas; y en segundo lugar, que la Filmoteca Española ha sabido jugar un papel de colaborador leal y no impositor como garante de las "esencias identitarias", un perfil bajo de colaboración leal mantenido durante décadas que ha evitado los recelos con las autonomías más centrífugas. Quizá sea porque en todos está el espíritu de los primeros internacionalistas de la FIAF que entendían la colaboración entre archivos por encima de las diferencias políticas.

La situación actual de cada una de ellas difiere en función de su tamaño, de la voluntad política de las instituciones de quienes dependen, y de la vocación internacional que poseen, por lo que podemos establecer y agruparlas en tres grupos diferenciados: (1) filmotecas autonómicas con un estatuto jurídico propio y que son miembros de pleno derecho o asociadas de la FIAF; (2) filmotecas autonómicas y/o locales que tienen un estatuto jurídico propio, pero no asociadas de la FIAF; (y 3) filmotecas llamadas así pero que no tienen un estatuto jurídico propio y muy limitadas de contenido. Dentro del primer grupo estarían: 
La Filmoteca Vasca. Se trata de una institución en su origen privada que ha ido derivando hacia el actual patronato con financiación pública del Gobierno Vasco y las diputaciones forales. Ha mantenido el criterio de ser exclusivamente un archivo con apenas una sala de proyección de aforo muy reducido. Con independencia de la futura localización en una sede mayor, centra su labor en aunar la producción de cine vasco, en su difusión, y en ser el depositario de las copias ganadoras del Festival de San Sebastián. Al tratarse del único archivo cinematográfico vasco, se ha convertido en una importante referencia para investigadores, productoras, televisiones, estudiantes etc.

Filmoteca de Cataluña. Tiene su origen en el traslado de proyecciones de la Filmoteca Española a Barcelona. Una vez realizado el traspaso de competencias, en 1981 se constituye como tal en 1981. Desde 2002 depende orgánicamente del Instituto Catalán de las Empresas Culturales y su funcionamiento está regulado por la ley catalana del cine de 2010. Destaca en los últimos años el traslado de las proyecciones a la nueva sede del Raval barcelonés, que persigue que las actividades de conservación se complementan con otras políticas básicas para la difusión del séptimo arte: proyecciones, exposiciones, progrmas formativos, festivales, etc.

Filmoteca Valenciana (IVAC). El Institut Valencià de l'Audiovisual i de la Cinematografia 'Ricardo Muñoz Suay' fue creado por la ley 5/1998, de 18 de junio, y en su estructura integró a la Filmoteca de la Generalitat Valenciana, creada en 1985. Incorpora en su denominación el nombre del cineasta, fundador y primer director de la Filmoteca valenciana, Ricardo Muñoz Suay. La Filmoteca Valenciana se encarga de llevar a cabo las tareas de recuperación, restauración, catalogación y conservación de material relacionado con la cinematografía y el audiovisual, además del estudio y difusión de la cultura cinematográfica.

Filmoteca de Andalucía. Fue creada por Decreto 295/1987, de 9 de diciembre e inició sus actividades en diciembre de 1989. Desde su origen, lleva a cabo una labor de investigación, recopilación y difusión del patrimonio cinematográfico andaluz. Esta actividad se complementa con un programa de proyecciones que aúna la revisión de los grandes referentes de la historia del cine con las últimas tendencias en este arte. Asimismo, la Filmoteca de Andalucía es también un espacio cultural, de encuentro y de participación para la sociedad civil.

CGAI. El Centro Galego de Artes da Image fue creado por Decreto 210/1989 del 5 de octubre de la Xunta de Galicia, que toma el testigo de la Filmoteca do Pobo Galego y del Archivo de la Imagen de Galicia, ambos creados a principio de los años 80. Aúna las dos vertientes, fotografía y cinematografía, en un centro que no tiene otro parentesco en España. Sus funciones aúnan la recuperación con la difusión, especialmente de aquellas dirigidas a proporcionar un mayor conocimiento de las artes de la imagen.

A este primer grupo de filmotecas que están asociadas a la FIAF habría que sumar a la propia Filmoteca Española. La pertenencia a la FIAF implica el cumplimiento de una serie de parámetros de calidad en cuanto a la homologación de los sistemas 
de conservación, de restauración, de proyección y de realización de labores de intercambio de fondos, lo que no quiere decir que quienes no pertenezcan al Club FIAF no los cumplan o sean de menor importancia: simplemente no están asociadas o no son miembros, y los motivos de estar o no estar en ese club pueden ser diversos. Así, en España conviven otras filmotecas territoriales, igualmente significativas (Grupo 2):

Filmoteca de Zaragoza. Inicia sus actividades en 1981 como una entidad dependiente del Ayuntamiento de Zaragoza, recogiendo los intentos, desde los años 30, de recoger en un centro todo el patrimonio fílmico aragonés. Se constituye como fundación pública, cuyo objeto y fines son el estudio y la difusión del cine preferentemente aragonés. Cuenta con departamentos independientes de conservación y de difusión, con programas educativos y de proyecciones estable.

Filmoteca Canaria. Creada en 1984, sus funciones se extienden a la conservación y difusión del patrimonio fílmico, videográfico y fotográfico generado en las islas. Desde 1992 la Filmoteca Canaria pasa a formar parte de la Sociedad Canaria de las Artes Escénicas y de la Música (SOCAEM), sociedad pública dependiente de la Consejería de Educación, Cultura y Deportes de Canarias. La Filmoteca Canaria se subdivide en a) un área de archivo y recuperación, con sede en Santa Cruz de Tenerife, y b) un área de difusión, con sede en Las Palmas de Gran Canaria.

Filmoteca Regional de Murcia. Después de una andadura sin estructura definida desde 1986, esta Filmoteca toma cuerpo jurídico en 2005, con el Decreto 81/2005, de 8 de julio que especifica que tendrá, entre otras funciones, las de recuperar, conservar y difundir el patrimonio cinematográfico de la Región de Murcia, así como satisfacer las demandas de formación, experimentación y prácticas cinematográficas. Después de un periodo muy activo, el cese de su director y las obras de su sede han vaciado de contenido la actividad de la Filmoteca.

Filmoteca de Castilla y León. Se crea por Orden de 29 de noviembre de 1990. Establece que los objetivos serán la recuperación, conservación, archivo, restauración, investigación y difusión de documentos cinematográficos audiovisuales en general. Asume una doble función básica: reunir y conservar todos los documentos fotográficos, cinematográficos y videográficos -antiguos y contemporáneos- que tengan algún tipo de relación con el marco geográfico e histórico de Castilla y León, y permitir el acceso a los mismos por parte de investigadores, estudiosos y personas interesadas, en general, por esas materias.

Filmoteca de Extremadura. Creada por Decreto 43/2002, de 16 de abril, mantiene la dualidad de conservación y difusión, pero después de enumerar las funciones más habituales de una filmoteca, desarrolla una cláusula abierta en la que se especifica que serán también todas aquellas derivadas del objeto propio de la Filmoteca. Tiene su sede en Cáceres aunque desarrolla actividades en Badajoz, Trujillo y Mérida.

Filmoteca Navarra. Nace por Acuerdo del Gobierno de Navarra, de 26 de enero de 2009, por el que se crea la fundación pública Instituto Navarro de las Artes Audiovisuales y la Cinematografía (INAAC), que incluye a la Filmoteca Navarra. Su misión 
primordial es la recuperación, archivo, conservación, investigación, y difusión de las películas y obras audiovisuales vinculadas con Navarra, así como de los materiales, equipos y cualquier otro elemento que sea de interés para el estudio del cine y el audiovisual en general, y del navarro en particular.

Filmoteca de Albacete. Nace en 2001 y es dependiente del Ayuntamiento de Albacete. Persigue la recuperación, investigación y difusión del arte cinematográfico en la ciudad de Albacete, así como en la Comunidad Autónoma de Castilla-La Mancha. Hay un proyecto pendiente por parte de la Junta de Castilla-La Mancha de extender su radio de acción a toda la comunidad autónoma, pero aún está en suspenso.

Existen finalmente en España otras experiencias filmotecarias que no han llegado a constituirse como tal en Filmoteca (Grupo 3). La riojana, de reciente aparición, es apenas un programa dentro de la Dirección de Cultura de la Comunidad; la balear, después de un primer intento fallido en 1987 aún está pendiente de su desarrollo; la cántabra es un programa de proyecciones en el marco del programa del Palacio de Festivales de Santander; la asturiana está actualmente derogada su regulación por el Decreto 169/2011 del Principado, y apenas constituye un programa inestable de proyecciones; por su parte ni la Comunidad de Madrid ni Ceuta ni Melilla tienen actividad filmotecaria propia como tal.

\section{Conclusiones}

A lo largo de la historia las filmotecas respondieron a la barbarie destruccionista de las tres primeras décadas del siglo XX motivadas por los efectos devastadores que la obsolescencia tecnológica tenía para con el patrimonio fílmico. La destrucción como hecho intrínseco al fenómeno fílmico tuvo su respuesta en el origen del movimiento filmotecario mundial que nació en la década de los de los 20 y principios de los 30 del siglo pasado, de la mano de diversos gobiernos y entidades privadas europeas.

El interés previo por la defensa de la cultura cinematográfica se ve roto en España a consecuencia de la Guerra Civil (1936-1939), que establece un doloroso paréntesis a toda construcción de una idea filmotecaria que no se retomará hasta los años 50, y que culminará finalmente con la constitución oficial en 1954 en Madrid de la Filmoteca española.

La Constitución Española de 1978 abre un nuevo marco de acción cultural descentralizado y abierto que desemboca en una proliferación a lo largo de las tres últimas décadas de quince filmotecas autonómicas, además de las tres locales y una estatal que configuran la actual diversidad y singularidad del mapa filmotecario español.

La situación actual de cada una de ellas, difiere en función de su tamaño, de la voluntad política de las instituciones de quienes dependen, y de la vocación internacional que poseen, lo que permite clasificarlas en tres grupos diferenciados: 1. Filmotecas con un estatuto jurídico propio que son miembros de pleno derecho o asociadas 
de la FIAF (Filmoteca Española, Filmoteca Vasca, Filmoteca de Catalunya, Filmoteca Valenciana, Filmoteca de Andalucía, CGAI); 2. Filmotecas que tienen un estatuto jurídico propio (Filmoteca de Zaragoza, Filmoteca Canaria, Filmoteca Regional de Murcia, Filmoteca de Castilla y León, Filmoteca de Extremadura, Filmoteca Navarra, Filmoteca de albacete); 3. Filmotecas, que aunque llamadas así, no tienen un estatuto jurídico o muy limitadas de contenido y/o atribuciones (Filmotecas riojana, balear, cántabra, y asturiana).

Pese a su indudable riqueza y singularidad hasta la fecha, el conjunto de la actividad filmotecaria española necesita ser revisada y actualizada ante el nuevo contexto digital. El conjunto del mapa filmotecario español necesita incorporarse a la discusión y reflexión urgente sobre qué papel deben jugar las filmotecas en un escenario digital. La identidad e incluso la supervivencia misma de éstas dependerá así de su capacidad de adaptación a las nuevas condiciones que imprimen las tecnologías digitales y que ponen en cuestión los cimientos de lo que ha sido su identidad, función y actividad cultural hasta la fecha.

\section{Bibliografía}

BORDE, R. (1991). Los Archivos Cinematográficos. Valencia: Ediciones IVAC-Filmoteca de la Generalitat Valenciana.

DEL AMO, A. (1991). "Las bases industriales de la conservación cinematográfica". En: Archivos de la Filmoteca, $\mathrm{n}^{\mathrm{o}}$ 10, Valencia: Instituto Valenciano de Cinematografía p. 14-33.

DELAMO, A.; FERNÁNDEZ, J. (2011). Conservación audiovisual en el inicio de la era digital. San Sebastián: Filmoteca Española-Filmoteca Vasca.

GARCÍA MANGAS, S. (1995). La filmoteca, centro de conservación del cine: el caso español [Tesis Doctoral].Santiago de Compostela: Universidad de Santiago de Compostela.

LOW, R (1997). The History of British Film. Oxford: Routlegde.

SEGUIN, L. (2002). "Film archives lost in a fire: An assessment". En: Quinzaine litteraire, $n^{\circ}$ 826, Paris: Selis Editeur.

SORIA, F. (1987). "Las Filmotecas". En: Cuadernos de la Filmoteca, n 3, octubre 1987, Valencia: Filmoteca Generalitat Valenciana.

SUNDHOLM, J. et al. (2006). Historical Dictionary of Scandinavian Cinema. Plymouth: Scarecrow Press.

SUROWEC, C. (2002). This Film is Dangerous. A Celebration of Nitrate Film. Bruxelles: FIAF.

TUBELLA, I.; ALBERICH, J. (2012). Comprender los Media en la sociedad de la información. Barcelona: Editorial UOC. 


\section{Notas}

1. Los únicos límites que tienen las productoras es la necesidad de depositar copias en las filmotecas, como así establece LEY 55/2007, de 28 de diciembre, del Cine, en su artículo 6: Protección del patrimonio cinematográfico y audiovisual.

2. Aforismo citado en el marco de la conferencia impartida por el pintor Juan Cuenca, que tuvo lugar en la Filmoteca de Andalucía el 3 de diciembre de 2009, con motivo de la proyección de la película "Film Experiencia nº 1 . Base teórica: Interactividad del espacio plástico" de Equipo 57.

3. La cronología de las personas que estuvieron al cargo de la Filmoteca Española, ha sido la siguiente: Carlos F. Cuenca. Director desde el 13 de febrero de 1953 hasta diciembre de 1970. Presidente desde el 11 de diciembre de 1970 hasta su muerte en 1977; Luis G. Berlanga. Presidente desde el 1 de enero de 1979 hasta el 31 de diciembre de 1982; Florentino Soria. Director desde el 17 de noviembre de 1970 hasta el 23 de marzo de 1984; Juan Antonio Pérez Millán. Director desde el 6 de junio de 1984 hasta el 5 de noviembre de 1986; Miguel Marías. Director desde el 5 de noviembre de 1986 hasta el 22 de diciembre de 1988; José María Prado. Director desde el 15 de julio de 1989 hasta hoy.

\section{Los Autores}

Pablo García Casado (Córdoba,1972) es Licenciado en Derecho por la Universidad de Córdoba, Máster en Gestión de Instituciones y Empresas Culturales de la Universidad de Barcelona, y Máster en Cinematografía por la Universidad de Córdoba. Ha desarrollado su labor en la gestión cultural en diversos ámbitos, entre los que destacan, la coordinación del Programa Arte y Creación Joven de la Junta de Andalucía, formar parte del equipo de redacción de la candidatura de Córdoba a Capital Cultural Europea 2016. Desde 2008 dirige la Filmoteca de Andalucía.

Jordi Alberich Pascual (La Bisbal de Falset, Tarragona, 1969), es Doctor por la Universidad de Barcelona (1998) y Profesor Titular de Universidad de Comunicación audiovisual y Publicidad en la Facultad de Comunicación y Documentación de la Universidad de Granada. Es miembro del laboratorio de investigación SECABA, e investigador colaborador del grupo de investigación SCI2S (Soft Computing and Intelligent Information Systems) y del Internet interdisciplinary Institute IN3, centro de investigación de excelencia de la Universitat Oberta de Catalunya. 